\title{
Applied Aspects of Blockchain Technology in Travel and Tourism Industry
}

Assoc. prof., PhD Velina Kazandzhieva

University of Economics - Varna, Varna, Bulgaria

velina_kaz@ue-varna.bg

\begin{abstract}
Blockchain technology is in the early stage of its development, but there's consensus about its potential. The technology is at an inflection point, with momentum shifting from "blockchain tourism" and exploration to the building of practical business applications. Tourism industry and blockchain have the possibility to become a powerful combination as the technology can bring safety and transparency of transactions. This article aims to examine the features of blockchain as an innovative technology and to present its more important advantages and applied aspects in the field of tourism. There are a growing number of emerging disruptors across travel industry, challenging traditional business models with the use of blockchain. Given some of the blockchain technology's characteristics and possibilities, this article is pointed towards important applications within the tourism.
\end{abstract}

Keywords: blockchain, tourism industry, advantages, applications.

JEL Code: O300; O330; Z30 DOI: https://doi.org/10.36997/IJUSV-ESS/2020.9.1.88

\section{Въведение}

Блокчейн, известна още като блокова верига, е сравнително нова технология, която революционизира ежедневието на хората, дори начина, по който те пътуват и организират туристически обиколки и ваканции. През последното десетилетие блокчейн е интересна и надеждна технологична иновация, поради своя голям потенциал да промени драстично вариантите, по които се съхраняват, използват данни и други източници на информация, включително и в туристическия сектор. Технологията подобрява сигурността на сделките и гарантира тяхната прозрачност, затова компаниите в туристическата индустрия все по-често експериментират с нея. Блокчейн може да се справи с липсата на доверие и да е достоверна, без да е необходимо да се вярва на някого.

Значителният потенциал и перспективите пред блоковата верига в туризма и пътуванията определят актуалността на настоящата разработка. Предмет на изследване в статията са същностните характеристики на блокчейн технологията и нейните особености. Oбект на проучване са предимствата и възможностите за приложение на блоковата верига в туристическата индустрия. Поставената научно-изследователска цел в статията е: на основата на анализиране на особеностите на блокчейн като иновативна технология, да се представят по-важните й преимущества и приложни сфери в туризма и пътуванията. Синтезирани са данни от глобално изследване на Deloitte относно нагласите към блоковата верига и е направена обща характеристика на реализирани туристически проекти на основата на технологията.

\section{1. Сыщност и особености на блокчейн технологията}

Появата на блоковата верига или веригата от блокове, по-известна в транслитерирания вариант от английски език блокчейн (blockchain) предизвика вниманието и интереса на предприемачите в цял свят, в т.ч. и на тези, в сферата на туризма. Технологията е популярна с въвеждането на криптовалутите и по-специално на биткойн. Най-кратко, веригата от блокове от бази данни може да се дефинира като протокол за предаване, верифициране и съхраняване на данни. Тя не е администрирана от централен сървър, а е мрежа от равноправни (peer-to-peer, P2P) участници, в която децентрализирани възли съхраняват копия на цялата блокова верига. Концепцията на блокчейн технологията, първоначално описана като верига от „блокове“, принадлежи на американските 
изследователи Stornetta и Haber (1991). Представена е като начин на ефикасно събиране и движение на множество фрагментни данни. По същество блокчейнът е главна отчетна (счетоводна) книга, която расте непрекъснато и събира записи/транзакции във времето. Технологията позволява децентрализирано управление на данни и създаване на децентрализирани организации, извьршващи децентрализирани процеси. Не съществува субект (човек или група) в блоковата верига, който да има контрол върху мрежата, а тя се управлява от участниците в нея.

На практика блоковата верига е метод на съхранение на информация в компютьрна мрежа, който е непрекъснато растящ списък от компютърни записи, наречени „блокове“, свързани помежду си и криптографски кодирани (Narayanan et al., 2016). Всеки „блок“ съдържа информация за предходния „блок“ и е удостоверен за време, което осигурява хронологична цялост - интегрираност на веригата назад до първия „блок“ (фигура 1). В блоковата верига могат да се записват транзакции между двама участници по начин, който е устойчив и подлежи на проверка (Iansiti, Lakhani, 2017). Участниците в мрежата са равноправни (Р2P) и спазват определен протокол за валидиране на новите „блокове“. Веднъж валидиран и записан, никой „блок“ не може да бъде променян, без да се изменят всички следващи го „блокове“. Участниците, наричани „пиъри“ (от англ. peer - равен, на същото ниво) са едновременно „снабдители“ и „потребители“ на ресурси, за разлика от традиционния клиентско-сървърен модел, където самите сървъри дават (снабдяват), а клиентите консумират (фигура 2).

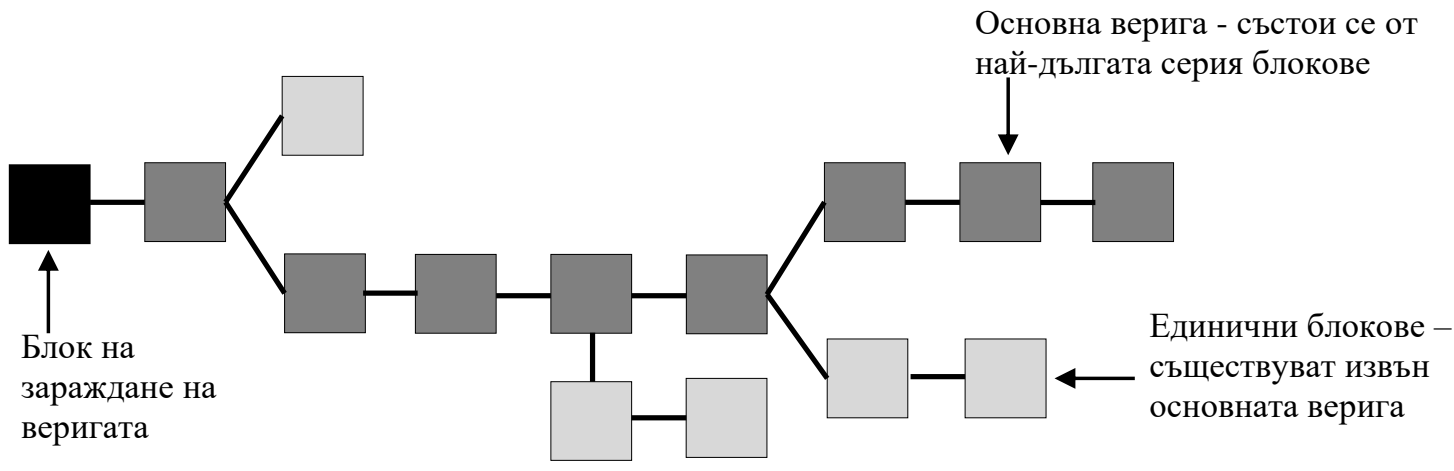

Фигура 1. Формиране на блокова верига

Възможностите за използване на блоковата верига нарастват експоненциално благодарение на: комбиниране с нарастващия капацитет на информационните системи за изчисляване и анализ на данни; засилване на свързаността; непрекъснато развитие на системите с изкуствен интелект. Блокчейн е комуникационен протокол и публичен регистьр, в който се „отбелязват“ в определена последователност, с висока степен на прозрачност и във форма, която не може да бъде променяна, всички сделки, извършвани между участниците в мрежата. „Верижно свързаните блокове“ се регистрират едновременно във всяко от устройствата, чрез които комуникират участниците в блоковите вериги. Сделките се извършват хоризонтално и се валидират от множество участници, което прави невъзможни промените или унищожаването на регистрации да се извършват от един единствен оператор. Това би трябвало да гарантира сигурността на обработката на данните и да създава благоприятни условия за укрепване на взаимното доверие между участниците в блоковите вериги. 


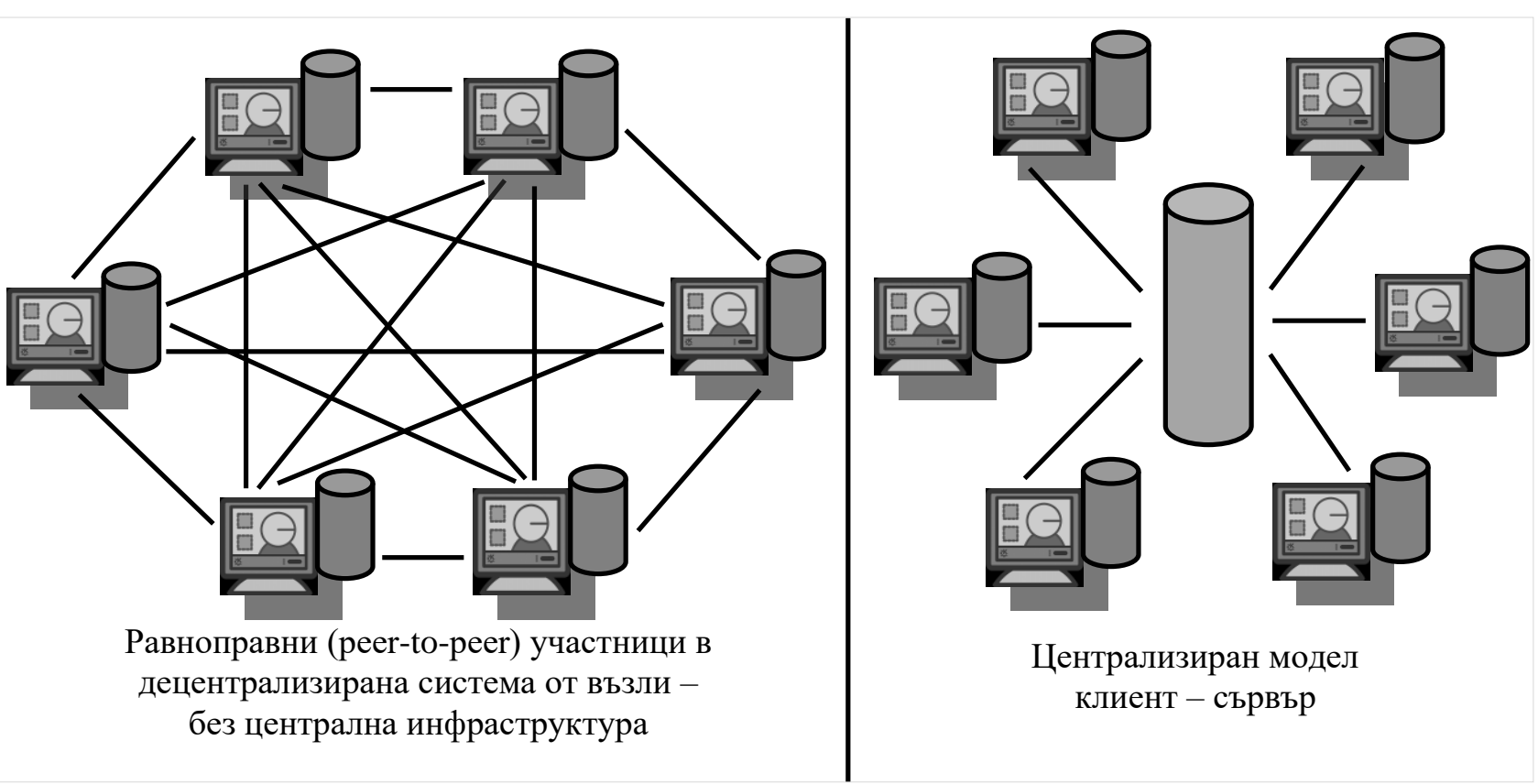

Фигура 2. Сравнение на децентрализирана и централизирана система

Блокчейн е интересен инструмент за ново прилагане на концепцията за сигурност на цифровите сделки. Поради тази причина технологията придобива финансова, социална, културна, икономическа и политическа стойност и полезност. Участниците в дадена блокова верига упражняват пряк контрол върху част от цялата верига и по този начин технологията се превръща в децентрализирана система, която е трудно да бъде „доминирана“ само от един участник, което повишава сигурността й. Сделките, които се осъществяват благодарение на блоковите вериги, могат да се проследят и видят от всички участници, затова операциите се извършват прозрачно, без намесата на „централен орган“ или на „трета“ страна, която да изпълнява функцията на задължителен партньор или посредник. Но, развитието на квантовите компютри, както и теоретичната възможност за „контролиране“ на значителен брой възли в мрежата, не премахва напълно рисковете от концентрация или контрол, както и от събиране на данни без съгласието и/или знанието на лицата, които са ги генерирали, и от концентрация на данните. Тези характеристики позволяват на технологията на блоковите вериги да разработва истински договори за автоматично изпълнение, наричани „интелигентни договори“, които дават възможност дадена сделка да се персонализира и детайлизира бързо, сигурно и хоризонтално. По този начин сертифицираната основна информация се превръща в приложимо право, което би могло да окаже въздействие върху много социални, икономически и политически практики. Пример за това е възможното развитие на цифрово управление във връзка с избори и системи за гласуване, социални и здравни услуги, управление на обществени поръчки.

Блоковата верига е сигурна технология с голямо приложение във финансовия свят. Алгоритмите в нея постигат консенсус за сигурност на транзакциите и изключват участници, които биха злоупотребили. Ползите от блокчейн са съществени, което води до употреба на технологията в най-различни сфери: гласуване; държавна администрация; финансови институции; логистика. Ключовите характеристики на технологията на блоковите вериги децентрализация, прозрачност, участие сред равнопоставени партньори, надеждност и доверие - са в съзвучие с основните организационни форми, чрез които работят предприятия и организации в съвременния дигитализиращ се туристически бизнес. Това е валидно още 
повече, ако мрежите по технологията са разработени с висока способност за оперативна съвместимост, която да позволи на потребителите да използват блокови вериги под формата на сътрудничество от различни устройства и инструменти. В бъдеще блокчейн ще се използва все повече и изследователите предричат значими трансформации в туристическата индустрия (Genkin \& Miheev, 2018; Gelter, 2017).

\section{2. Предимства на блокчейн технологията в туризма}

Блокчейн е технология, която осигурява прозрачност и доверие, надеждност и сигурност чрез добавяне на транзакции в разпределена книга, които не могат да бъдат фалшифицирани. Приложението на блокчейн в туризма позволява на клиентите да взаимодействат директно със заинтересованите страни. По този начин технологията елиминира посредници и резервационни агенции на трети страни. Освен това, в туристическата индустрия и хотелиерството се изпълняват интелигентни договори, свързани с плащанията на туристите. Това гарантира транзакционен портфейл с общ и уникален вид. Туристите могат да резервират билети за пътуване, да правят хотелски резервации, както и да резервират в ресторанти от едно приложение, базирано на блокчейн технологията. Основните предимства на приложението й в туристическата индустрия са представени на фигура 3.

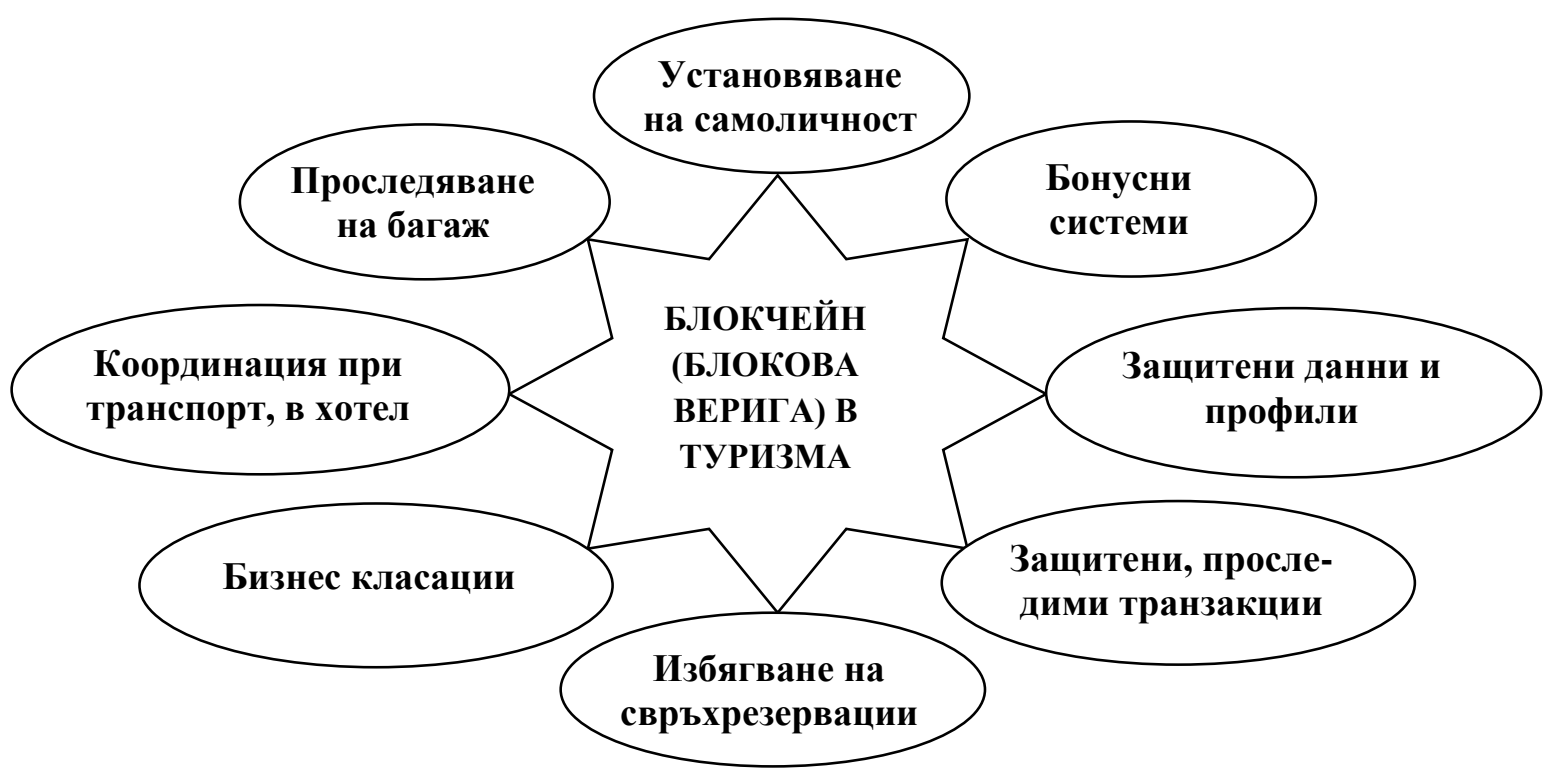

Фигура 3. Предимства на технологията блокчейн в туризма

Проследяване на багажи и вещи: извършва се автоматизирано благодарение на технологията блокчейн. Всяка идентификация на туриста позволява управление на неговия профил, свързан с асоциирания с пътника багаж. Проследяването му е възможно на всички етапи от пътуването и престоя в дестинацията. Блокчейн е подходяща технология за проследяване на местонахождението на багажа, особено по време на международни обиколки и ваканции. С помощта на децентрализирана база данни е възможно да се споделят данни за наблюдението между туристическите компании, да се проследява и да се знае къде е багажът по всяко време, включително обмен на информация между летищни оператори, авиокомпании, охранителни и наземни служби, хотели и туроператори.

Проверка на самоличността на пътника: туристите трябва многократно да се легитимират и да показват лични документи на различни етапи от пътуването: при резервации на услуги, качване в самолет, настаняване в хотел, наем на кола и др. Тъй като 
блокчейнът добавя данни за транзакции към всички възли, пътникът може да удостоверява по безхартиен начин самоличността си по време на всички етапи от пътуването. Не се изискват чести проверки на личните документи на туристите, което гарантира удобство и безпроблемно изживяване за посетителите.

Бонусни системи: почти всяка туристическа компания предоставя стимули и прилага програми за лоялност за своите клиенти, а целта е да ги превърне в мнократни посетители. Технологията блокчейн може да улесни предоставянето на стимули и награди като позволи на туристите да проверяват спечелените от тях бонус точки. Натрупаните точки могат да се обменят като посетителите инициират други плащания и приходи за туристическите компании.

Защциени данни и профили: всички транзакции, направени чрез блокчейн, са проследими и проверими, благодарение на сигурни и надеждни точки за контрол и възможности за отстраняване на нередности. По този начин се поддържа сигурността на посетителите и се гарантира възстановяване в случай на злоупотреби. Чрез използване на блокчейн всяка транзакция се оповестява в публичното пространство, а заинтересованите страни (потребители и доставчици) намаляват рисковете от измами до минимум.

Избягване на свръхрезервации: блокчейн технологията може да избегне дублиране на резервации, особено в празничните и ваканционните периоди от годината. В такива ситуации, поради голямо натоварване на централните сървъри за разплащане на хотели, авиокомпании, ресторанти и други, са възможни неуспешни или многократни плащания.

Бизнес рейтинги: съвременните туристи често пишат отзиви и на тяхна основа се правят бизнес рейтинги и класации на различните доставчици на услуги. Понякога оценките за опита на посетителите може да са неточни, неясни и подвеждащи. Освен това, поради ожесточената пазарна конкуренция и стремежът за постоянно увеличаване на печалбите, някои туристически компании (хотели, ресторанти, туроператори) предоставят фалшиви отзиви на клиентите. Тъй като блокчейн по същество е книга с публичен достъп, надеждна и защитена от фалшифициране, истинските отзиви са видими за клиентите. Технологията гарантира по-добра прозрачност в системата за наблюдение на потребителските мнения и оценки, и увеличава доверието на туристите.

\section{3. Приложения на блокчейн технологията в туризма}

В научната литература са разработени различни варианти на групиране на блокчейн приложения в туризма. В повечето случаи те са следствие на характеристиките на технологията, които са проявени във вече реализирани проекти в индустрията. Например, в хотелиерството блокчейн се прилага за управление на наличностти и за резервации. В първия случай се администрират операциите по настаняване, престой и изпращане на госта, а във втория, се предлага потребителски интерфейс и обработка на данни в и извън организацията. В транспортния сектор, потенциальт на технологията е особено подходящ за дейността на авиокомпаниите. Групирането на приложенията на блокчейн в туризма, представено в таблица 1, не е напълно завършено. Технологията е в процес на развитие, възникват нови приложни сфери, които в някои случаи се припокриват, заради сложността и очакваните дългосрочни последици от блокчейн (Treiblmaier, 2020).

Самоличност, управление на лични данни и поверителност. Блокчейн е много подходяща технология за еднозначно определяне на самоличност на всеки човек. Според Bell \& Hollander (2018), в близко бъдеще, споделянето на информация за самоличност между различни доставчици и блокови вериги ще доведе до глобална идентичност на пътника. Технологията е подходящо решение срещу кражба на самоличност, което е особено важно за туристите, които често трябва да предоставят лични документи при регистрация за полет, в хотел, при наем на кола и др. Идентификаторите на самоличност съдържат криптографски защитени кодове и позволяват проверка без да се предоставя лична информация (Dogru et al., 
2018). Лесното и бързото удостоверяване на самоличността е и от полза за туристическите компании (HTNG, 2018; Goudarzi \& Martin, 2018). Базираните на блокчейн решения за самоличност могат да споделят избрани данни в съответствие с приложимия закон. Според изискванията на съответни органи, може да се добави и биометрична информация (пръстови отпечатьци, лицево или ирис разпознаване).

Таблица 1. По-важни блокчейн приложения в туризма

\begin{tabular}{|c|c|c|c|c|c|}
\hline \multicolumn{3}{|c|}{$\begin{array}{c}\text { Самоличност и управление на } \\
\text { поверителността }\end{array}$} & \multicolumn{3}{|c|}{$\begin{array}{c}\text { Сьдържание, резервации, продажба на } \\
\text { билети }\end{array}$} \\
\hline $\begin{array}{c}\text { Самоличност } \\
\text { на пътника }\end{array}$ & $\begin{array}{l}\text { Персонали- } \\
\text { зация }\end{array}$ & $\begin{array}{c}\text { Проследяване } \\
\text { на багаж }\end{array}$ & $\begin{array}{l}\text { Хотели, наем } \\
\text { на коли }\end{array}$ & Застраховка & Полети \\
\hline \multicolumn{3}{|c|}{$\begin{array}{c}\text { Управление на имуществото } \\
\text { (собствеността) }\end{array}$} & \multicolumn{3}{|c|}{$\begin{array}{c}\text { Управление на } \\
\text { лични данни }\end{array}$} \\
\hline $\begin{array}{c}\text { Планиране } \\
\text { на капацитет }\end{array}$ & $\begin{array}{c}\text { Пряка } \\
\text { дистрибуция }\end{array}$ & $\begin{array}{c}\text { Мрежа от } \\
\text { доставчици }\end{array}$ & $\begin{array}{c}\text { Автентичност } \\
\text { на отзиви }\end{array}$ & $\begin{array}{c}\text { Рейтинги и } \\
\text { класации }\end{array}$ & Верификация \\
\hline \multicolumn{3}{|c|}{$\begin{array}{c}\text { Дигитални плащания и данъчни } \\
\text { съответствия }\end{array}$} & \multicolumn{3}{|c|}{$\begin{array}{c}\text { Програми за лоялност и персонализиран } \\
\text { маркетинг }\end{array}$} \\
\hline $\begin{array}{l}\text { Трансгранич- } \\
\text { ни преводи }\end{array}$ & Криптовалута & $\begin{array}{c}\text { В2В } \\
\text { съглашения }\end{array}$ & Отстъпки & $\begin{array}{c}\text { Стимули и } \\
\text { награди }\end{array}$ & Бонуси \\
\hline
\end{tabular}

Източник: Адаптирано по: Kwok, Koh, 2019.

Онлайн отзивите са от първостепенно значение за клиентите в туризма, но тяхната автентчиност и надеждност често е под въпрос. Сертифицирането на отзиви, преди съхраняването им в блокчейн, чрез подпис с частен ключ, може да повиши доверието в публикуваната онлайн обратна връзка (Treiblmaier \& Önder, 2019; Pilkington, 2017). Но това не гарантира напълно надеждността на клиентските отзиви и е възможно нелоялни или предубедени мнения да не могат да бъдат премахнати след публикуване (Nam et al., 2019). Споделянето на лична информация води до проблеми с поверителността, условията и достъпа до лични данни. Блокчейн предлага широки възможности - от всеобхватно наблюдение до индивидуално определяне на данни за споделяне според принципите за избягване и минимизиране на информацията.

Съдържание, резервации и продажба на билети. Актуализирането на клиентския интерфейс, най-често корпоративен уебсайт, е голямо предизвикателство за туристическите организации. Например, когато в хотелите се обновява, ребрандира или се добавят нови съоръжения, е необходима актуализация на съдържанието, в т.ч. текстови описания, снимки и видеоклипове. В подобни случаи блокчейн може да е централно място за съхранение на данни, за резервации, за продажба на билети (чрез стандартен протокол) и за премахване на черни пазари (HTNG, 2018). Управлението на продажбите на самолетни билети е сложен процес, с многобройни бизнес партньори, който може да се улесни и ускори чрез блокчейн решения (Goudarzi \& Martin, 2018).

Управление на имуществото (инвентара). Имуществото в туризма се отнася до брой стаи в хотелиерството, или брой места при авиокомпания. Блокчейн подпомага предоставянето на информация относно наличностите, динамиката на продажбите, както и споделянето на тази информация между заинтересованите страни. В хотелиерството, базираните на блокчейн решения могат да заменят системите за управление на собственост (PMS) и централните резервационни системи (CRS), свързващи различни възли от канални мениджъри и глобални дистрибуционни системи (GDS). Новите системи са в състояние допълнително да синхронизират и координират данните с търговски обекти, посещавани от 
клиентите, вкл. онлайн туристически агенции (ОТА), традиционни турагенти и туроператори. Сложността на обработката и предаването на данни често изисква от хотелиерите и авиокомпаниите да плащат комисиона или такса на трети страни. Технологията блокчейн може директно да свърже доставчиците с търговските обекти, насочени към клиентите и така да премахне посредниците и свързаните с тях разходи (HTNG, 2018).

Едно от интересните проявления на блокчейн са интелигентните договори алгоритми, записан в компютърен код, които при възникване на предварително определени условия, се изпълняват автоматично. Тези условия се потвърждават от надеждни източници на данни, които усещат и проверяват външна информация и я подават на блоковата верига. Терминът „интелигентен договор“ всъщност е подвеждащ, защото това не са договори в правното значение на понятието. В сегашното си състояние тези програми не са „умни“ в смисъл, че се научават да се адаптират към промените в околната среда, а са силно детерминирани, тъй като тяхното изпълнение в различни възли трябва да доведе до идентични резултати, а предварителните условия трябва да бъдат точно дефинирани възможно най-рано. Програмирането и автоматичното изпълнение, независимо от човешката намеса, предлага множество възможности за туризма, като намаляват усилията, необходими за изпълнение на договора, мониторинга и контрола на изпълнението, фактурирането (Goudarzi \& Martin, 2018).

Интелигентните договори могат да предизвикат незабавно плащане след запис на транзакция въз основа на договорните условия, което улеснява сътрудничеството между хотели и туристически агенции. Освен това, операциите по настаняване в хотела могат да се елиминират чрез предоставяне на стаи на гостите с цифров ключ на блокчейна, след заплащане на определената цена. Аналогично при наемането на апартаменти (Airbnb) и автомобили, оборудвани с ключалки, управлявани чрез блокчейн. При авиокомпаниите отчитането на приходите е по-сложно, тъй като те включват не само продажбата на билети, но и такси за избор на определена тарифа, разходи за багаж и обслужване по време на полет. Правилата за споделяне, определени от IATA и авиокомпаниите, реализирани с помощта на интелигентни договори, водят до иновативни направления на общите приходи и бързото им разпределяне (Irvin \& Sullivan, 2018). Умните договори улесняват застраховката на полета, като автоматично изплащат уговорената сума в случай на забавяне или анулиране (Dogru et al., 2018). В хранителната индустрия се използват интелигентни договори за постоянни поръчки, базирани на блоковата верига (Willie, 2019).

Дигитални плащания и данъчни съответствия. Önder \& Treiblmaier (2018) считат, че широкото разпространение на криптовалути може значително да повлияе на плащанията в туристическата индустрия. Това включва и използването на токен устройства за разплащане. Някои дестинации (Сан Франциско, Берлин, Любляна, Цуг, Токио, Малта, Прага и др.) вече експериментират с криптовалута за жители и туристи, за да получат конкурентно предимство. Блокчейн мрежите улесняват трансграничните парични преводи и избягват проблеми с конвертирането на чуждестранна валута. Като цяло, премахването на комисионите води до намаляване на оперативните разходи на пазарните субекти в туристическата индустрия (Kwok \& Koh, 2019). Настоящата пазарна структура е доминирана от посредници, които налагат значителни комисиони и такси. Използването на биткойни или токени при плащане може да направи пазара по-малко йерархичен и да подпомогне създаването на ефективни бонусни системи за туристи, които предоставят обратна връзка в сайтовете за отзиви (Nam et al., 2019). Друга интересна област са данъците, която е усложнена от факта, че резервациите понякога подлежат на данъчно облагане на различни равнища (град, окръг, област, държава, между държави). В такива случаи блокчейн технологията дава възможност на данъчните власти да публикуват данъчните структури, а 
интелигентните договори автоматично прехвърлят данъци и платците получават потвърждение като доказателство за извършеното данъчно плащане (HTNG, 2018).

Програми за лоялност и персонализиран маркетинг. Сыществуващите програми за лоялност създават допълнителни административни разходи, а ползите не са особено ясни за клиентите. Голяма част от натрупаните точки не се осребрявата, а потребителите са склонни да избират програми, които ги привличат най-много (Pilkington, 2017). Тъй като не е ясно кога клиентът ще откупи точка или миля, разходите остават неизвестни и се натрупват, но не могат да бъдат признати (Irvin \& Sullivan, 2018). Използването на токени за лоялност, които се обменят свободно създава конкурентен пазар, предоставящ на компаниите обратна връзка за състоянието на програмите им за лоялност. Освен това, токените са лесно приложими в различни отрасли (Dogru et al., 2018). Използването на портфейли за лоялност, проследяващи токени между партньори и видове покупки, позволява свързване и обработка на транзакции в реално време. Също така се съгласува и управлява обмена на точки, използват се интелигентни договори за координация и осигуряване на пълен одиторски контрол (Irvin \& Sullivan, 2018). Типични транзакции на програма за лоялност, обработвани чрез блокчейн, включват прехвърляне на точки между сметки, обмен на точки между различни програми, групиране на оферти за обратно изкупуване на различни партньори (HTNG, 2018). Информацията, събрана в различните програми за лоялност, подобрява персонализирания маркетинг на компаниите и повишава неговата ефективност, но може да предизвика и сериозни опасения относно клиентската поверителност.

\section{4. Реализирани проекти в туризма на основата на блокчейн технология}

Блокчейн технологията става е все по-популярна сред бизнеса по целия свят. И докато в САЩ и някои западноевропейски държави тя набира голяма инерция, в Централна и Източна Европа все още приемането й е в начален етап. Това показват резултатите от глобално поучване на Делойт през 2018 г., проведено сред 1053 глобални мениджъри, ангажирани с блокчейн, от седем държави и девет индустрии (Deloitte, 2018). Като цяло, се наблюдава категорично убеждение, че в дългосрочен план въздействието на блокчейн ще трансформира бизнеса. Половината от анкетираните в Централна и Източна Европа смятат, че потенциалът на блокчейн е донякъде преувеличен, но 45\% от тях са убедени, че технологията ще промени из основи тяхната индустрия, а компанията им ще загуби конкурентно предимство, ако не приеме използването й. Само 42\% от участниците в проучването считат, че техният изпълнителен екип притежава задълбочено разбиране на технологията. Почти $60 \%$ от анкетираните смятат, че решенията, базирани на блокчейн, са по-сигурни от традиционните. На глобално ниво се наблюдава процес, в който технологията е в т.нар. точка на инфлексия с инерция, която се измества от „блокчейн туризъм“ и проучване на потенциала на технологията за създаване на приложения в бизнес практиката. Това се отнася най-вече за дигиталните компании, в сравнение с традиционните, които все още работят над процеса на въвеждане на дигитални технологии в съществуващи бизнес операции и протоколи.

Секторът на финансовите услуги е сред първите, който проучи блокчейн и е глобално признат с висок потенциал да бъде наистина повлиян от технологията. По-голямата част от анкетираните считат, че тя ще бъде от съществено значение за финансовата индустрия, но няма драстично да преобрази целия пазар. Една четвърт от тях вече са участвали в обединения с други субекти, за да проучат възможностите при потенциални случаи на употреба на блокчейн. 61\% от анкетираните във Франция и Великобритания са на мнение, че технологията е с широки възможности за приложение извън финансовия сектор. В Централна и Източна Европа 2/3 от анкетираните смятат, че блокчейн предлага много повече от това да осигури нова технология за разплащания и ще има ефект върху няколко индустрии, освен финансовия сектор. 76\% от респондентите от Централна и Източна Европа 
споделят идеята, че блокчейн ще бъде приет като мейнстрийм технология, но само $27 \%$ от тях планират да заменят част или цялата система, която използват, с иновации, базирани на новата технология. Повечето от участниците в проучването отбелязват, че все още не са започнали да инвестират в блокчейн технология, само $1 / 4$ от анкетираните твърдят, че са направили инвестиции досега, но почти $30 \%$ заявяват, че ще инвестират поне 100 хил. евро в нея в бъдеще. В туристическия сектор около $72 \%$ от анкетираните поставят блокчейн адаптивността като решаващ фактор за успех на процесите в обхвата на смарт туризма. По отношение на влиянието върху производителността на различните блокчейн модели, се установява, че разрешените или частните версии, ще са по-приложими в туристическата индустрия, в сравнение с публичните, каквито са Биткойн или Етериум.

Отделът по туризъм и маркетинг на Дубай стартира преди три години инициатива Cмaрm myризъм 2.0, за да използва блокчейн на туристическия пазар за пътувания от типа В2В. Проектьт позволява на хотели и туроператори да изпълняват интелигентни договори чрез технологията като същевременно предлагат оферти директно на клиентите чрез персонализирани приложения за социални платформи. Прозрачността при плащанията и проследяването на парите на потребителите се извършва чрез Arabianchain, който е обществено достъпен проект с отворен код, базиран на блокчейн. На глобално равнище проектът се реализира чрез интелигентни договори и внедряване на децентрализирани приложения за криптовалути за осигуряване на транзакциите.

Блоковата верига може да се използва и за насърчаване на туристическите посещения. От средата на 2016 г. фондацията Dubai Future работи по програма, стимулираща туризма под наименованието Dubai Points (Loyyal, 2016). Системата е разработена на основата на платформата блокчейн и лоялна договорна технология - Loyyal. Дубайските точки могат да се печелят и изкупуват в участващите обекти на основата на уникалното поведение на туристите, както и данни за време от деня, предишен туристически опит, възраст, местоположение и др. Сред потвърдените участници са местна авиокомпания, Jumeirah, Flyin, Privity, Digitus, Международен центьр за кулинарно изкуство, SquareCircle Tech, Фондация Dubai Future и др. компании.

Програмата Dubai Points e разработена на основата на публично-частно партньорство, за да се стимулира туризма чрез използването на блокчейн и на интелигентни договори. В настоящата Р2P ера блоковата верига позволява обмен на бизнес данни, без да е задължително страните по сделките да си имат доверие, тъй като системата не подлежи на подмяна и фалшификация. Сложните и дълги процеси по договаряне са по-бързи, по-евтини и опростени. Програмата дава възможност за персонализирано обслужване и лични връзки с всеки посетител като насърчава посещенията на разнообразни места, свързани с историята и културата на Дубай, които съответстват на потребителските интереси и предпочитания. При посещенията се получават бонус точки, които се изразходват според желанията и потребностите на туристите. Чрез изтегляне на Loyyal апликация потребителят се регистрира и така се формира индентификационен номер за съответния блокчейн. Посетителите потвърждават, че са посетили обектите чрез геолокация или с функцията за добавена реалност, вградена в приложението. С него туристьт може да направи снимка на посетения обект и да печели награди чрез точките, които събира. Те могат да се използват за допълнителни ползи като натрупване на баланс в SIM карта, за храни и напитки, за автомобилни услуги и др. Блоковата верига позволява мащабен поглед върху навиците на посетителите: причини за посещения на определени дестинации; предпочитани забележителности, места и атракции; видове покупки и др.

Технологията на блоковите вериги е вече възприета от ТУИ груп и внедрена в системите за заявки, резервации и плащания (Sixtin, 2017). Туроператорьт е първата голяма туристическа компания, която използва блокчейн за осигуряване на директен достъп до данните за хотелски капацитети, елиминирайки онлайн посредници като Expedia и Booking. 
Чрез технологията може да се оспори лидерството на подобни компании, в т.ч. и Airbnb, в онлайн резервациите за хотелско настаняване, наеми на имоти и организацията на пьтувания.

Туристическата компания Cool Cousin е основана през 2016 г. и вече има над половин милион потребители от цял свят (Cool Cousin, 2017). Тя е децентрализирана туристическа агенция от равноправни участници, свързани от типа „всеки към всеки“ (Р2Р). Агенцията осигурява оптимизиран интерфейс, където потребителят може да се свърже с местни жители от конкретни градове или населени места и да планира пътуването си, както и да получи съвети за хотели, туристически обекти и специални събития. По този начин агенцията елиминира фалшивите профили на туристическите компании, създадени от рейтингови уебсайтове, базирани на сложните механизми на изкуствения интелект. Бизнес моделът на агенцията се захранва от специална криптовалута (CUZ). Целта на компанията е да подпомогне посетителите чрез ускоряване и опростяване на процеса на тьрсене на консултации и съвети при посещения на туристически места, съответстващи на уникалните им потребности. По-голяма част от процеса на планиране на пътуването обхваща определяне на най-важните обекти за посещение в дадена дестинация и нейните потенциално атрактивни места.

Базираната в Европа компания LockTrip (start-up) е създала функционална туристическа услуга, използвайки блокчейн технологията. Иновативната платформа на компанията предлага 1000 авиокомпании, 521 хил. хотели и ваканционни имоти по целия свят, със средна отстьпка от почти $20 \%$ в сравнение с други сайтове за резервации като Booking, Expedia и Airbnb (Whitepaper, 2017). Настаняване с 0\% комисиона и без посредник, може да бъде резервирано директно през съществуващия бета-пазар на LockTrip (https://beta.locktrip.com/). Услугата помага на потребителите да спестят до 17\% при резервиране на хотели в Европа и над $23 \%$ в САЩ. От компанията отбелязват, че популярните сайтове (Airbnb, Booking) таксуват хотелите с комисиона от 15\% до 30\%, което по-късно оказва влияние върху крайната цена за гостите (LockTrip, 2019). Платформата предлага и полети, на цени около 5\% по-евтини от конкуренцията.

Разплащанията се извършват c LOC-токени, тъй като основна характеристика на блоковата верига е възможността мрежата да създава собствени криптовалути във вид на токени, чиято отновна функция е да служат като платежно средство. С тях потребителите могат да заплащат услуги или да обменят токени срещу „истински“ пари (чрез автоматично превалутиране). Потребителите, които не са крипто ориентирани, могат да правят резервации, като използват кредитна карта по същия начин, както на всеки друг сайт за пътувания. Всяка резервация е заключена в интелигентен договор до приключване на поръчката. Компанията твърди, че резервирането чрез техния пазар е много по-достьпно и сигурно за гостите, в сравнение с традиционните начини. Бизнес моделът се поддържа и от плащания на хотелите, за да бъдат промотирани на по-предни позиции в официалния пазар и мобилното приложение на LockChain (Chakhova, Kosheleva, 2018). В платформата, хотелите и ваканционните имоти също имат отзиви, снимки, оценки и т.н. Гостите, отседнали в хотел, получават обратно неголяма сума, веднага след като напишат отзив. Така, за кратко време се натрупва солидна база от мнения и оценки за всеки хотел в мрежата, подобно на TripAdvisor и Booking.

Туристическата компания SITA, която предоставя ИТ поддръжка и телекомуникации за авиокомпаниите, предлага метод за рационализиране на идентификацията на пътниците. Той е основан на блокчейн и внедрява единна и сигурна система за биометрична идентификация, която позволява на туристите да докажат своята самоличност чрез смартфон или друго преносимо устройство по време на цялото пътуване. Актуални примери за платформи в туристическата индустрия, на основата на блокчейн, са представени в таблица 2, заедно с тяхната обща характеристика. 


\section{IZVESTIA JOURNAL OF THE UNION OF SCIENTISTS - VARNA}

Таблица 2. Блокчейн платформи в туристическата индустрия

\begin{tabular}{|l|l|}
\hline \multicolumn{1}{|c|}{ Платформи } & \multicolumn{1}{c|}{ Обща характеристика } \\
\hline LockChain & $\begin{array}{l}\text { Функционира като отдава под наем имоти, без посредници и без } \\
\text { комисиони. }\end{array}$ \\
\hline $\begin{array}{l}\text { BeeToken/ } \\
\text { Beenest }\end{array}$ & $\begin{array}{l}\text { Платформа за споделяне на дома, без комисиона, поддържа } \\
\text { сигурността на потребителите. Предлага протоколи за плащане, } \\
\text { репутация и арбитраж. }\end{array}$ \\
\hline Winding Tree & Проследяване на багаж, лесно, безопасно и сигурно. Прозрачност. \\
\hline ShoCard \& SITA & Децентрализирана база данни за управление на самоличност. \\
\hline Trippki & Бонусна система за лоялност на клиентите. \\
\hline TUI Bed-Swap & $\begin{array}{l}\text { Преместване на наличности между различни точки на продажба и } \\
\text { гъвкави маржове на продажбите. }\end{array}$ \\
\hline
\end{tabular}

\section{Заключение}

Блокчейн технологията все още е в ранен етап на развитие. Сред изследователите има консенсус относно нейния значителен потенциал, но голямото предизвикателство е свързано с определяне на комплексните влияния върху отделните туристически сектори: транспорт и хотелиерство, туристически агенции и туроператори, ресторантьорство, атракции и др. Основни предизвикателства са самоличността и стандартизацията. По своята същност технологията би могла да бъде значително препятствие по отношение на личните данни. В бъдеще има потребност от по-голяма защита на идентичността на потребителите (като GDPR) чрез увеличаване на специфичните разпоредби относно личната информация в мрежата и нарастващото използване на персонализирания маркетинг в нея. Стандартизацията също е важно предизвикателство, защото всяка туристическа компания може да създаде собствена мрежа със специфични алгоритми (криптовалути). По този начин комуникацията между различните системи много се усложнява. Внедряването на технологиите в туристическата индустрия също променя и туристическото поведение. Блокчейн има потенциала да се адаптира към трансформиращите се потребности и предизвикателства пред посетителите, за да осигури по-сигурен, надежден, спокоен и удобен начин за пътуване и ваканция.

\section{References}

1. Bell, A., \& Hollander, D. (2018) Blockchain and Distributed Ledger Technology at Travelport. A Travelport White Paper. [Online] Available from: https://www.travelport.com/sites/default/ files/travelport-blockchain-whitepaper.pdf [Accessed 17/10/2020].

2. Chakhova, D., Kosheleva, A. (2018) Challenges and perspectives for the development of blockchain tourism in the Russian regions (case study of the Kaluga region). Regional economy and management: Electronic Scientific Journal, 53.

3. Cool Cousin (2017) Cool cousin- a travel company powered by blockchain. [Online] Available from: https://steemit.com/coolcousin/ [Accessed 13/10/2020].

4. Deloitte (2018) Global blockchain survey breaking blockchain open. [Online] Available from: https://www2.deloitte.com/us/en/pages/consulting/articles/innovation-blockchain-survey.html. [Accessed 08/10/2020].

5. Dogru, T., Mody, M., \& Leonardi, C. (2018). Blockchain Technology \& its Implications for the Hospitality Industry. Boston Hospitality Review. [Online] Available from: https://www.bu.edu/ bhr/2018/02/13/blockchain-technology-its-implications-for-the-hospitality-industry/ [Accessed $17 / 10 / 2020]$.

6. Gelter, H. (2017) Digital Tourism - An Analysis of Digital Trends in Tourism and Customer Digital Mobile Behavior. [Online] Available from: http://www.lme.fi/media/vae-outcomes/rdresults/report-visit-arctic-europe-mission-3-summary-2.pdf [Accessed 07/10/2020]. 
7. Genkin, A., Miheev, G. (2018) Blokcheyn. Kak eto rabotaet i chto zhdet nas zavtra. Moskva: Alypina Pablisher.

8. Goudarzi, H., \& Martin, J. I. (2018) Blockchain in Aviation. [Online] Available from: https://www.iata.org/publications/Documents/blockchain-in-aviation-white-paper.pdf. [Accessed 06/10/2020].

9. HTNG. (2018) Blockchain for Hospitality. [Online] Available from: https://www.hospitalitynet. org/file/152008497.pdf [Accessed 27/09/2020].

10. Iansiti, M., Lakhani, K. (2017) The Truth About Blockchain. January-February 2017 Issue, Harvard Business Review

11. Irvin, C., \& Sullivan, J. (2018) Using Blockchain to Streamline Airline Finance. [Online] Available from: https://www2.deloitte.com/us/en/pages/consulting/articles/airlines-blockchainfinance.html [Accessed 15/10/2020].

12. Kwok, A., Koh, S. (2019) Is blockchain technology a watershed for tourism development? Current Issues in Tourism, 22(20), pp. 2447-2452.

13. LockTrip (2019) Blokcheyn rezervatsionna platforma, sazdadena ot balgarin. [Online] Available from: https://cryptodnes.bg/blokcheyn-rezervatsionna-platforma-sa [Accessed $11 / 10 / 2020]$.

14. Loyyal (2016) Loyyal Announces Blockchain Based Tourism Program with Dubai Future Foundation. [Online] Available from: https://medium.com/@Loyyal/ [Accessed 07/10/2020].

15. Nam, K., Dutt, C. S., Chathoth, P., \& Khan, M. S. (2019) Blockchain technology for smart city and smart tourism: Latest trends and challenges. Asia Pacific Journal of Tourism Research. DOI: 10.1080/10941665.2019.1585376

16. Narayanan, A., Bonneau, J., Felten, E., Miller, A., Goldfeder, S. (2016) Bitcoin and cryptocurrency technologies: a comprehensive introduction. Princeton: Princeton University Press.

17. Pilkington, M. (2017) Can Blockchain Technology Help Promote New Tourism Destinations? The Example of Medical Tourism in Moldova. [Online] Available from: https://papers.ssrn.com/ abstract=2984479 [Accessed 30/09/2020].

18. Sixtin, E. (2017) TUI tourism group will adopt Ethereum blockchain technology. [Online] Available from: https://btcmanager.com/ [Accessed 13/10/2020].

19. Stornetta, W., Haber, S. (1991) How to Time-Stamp a Digital Document. Journal of Cryptology. Springer, 3(2), pp. 99-111.

20. Treiblmaier H. (2020) Blockchain and Tourism. In: Xiang Z., Fuchs M., Gretzel U., Höpken W. (eds) Handbook of e-Tourism. Springer, Cham

21. Treiblmaier, H., \& Önder, I. (2019) The Impact of Blockchain on the Tourism Industry: A Theory-Based Research Framework. In H. Treiblmaier \& R. Beck (Eds.), Business Transformation through Blockchain - Volume II (pp. 3-21). Cham, Switzerland: Palgrave Macmillan.

22. Whitepaper (2017) LT BlockChain, Ecosystem \& Marketplace DAPP. [Online] Available from: https://locktrip.com/whitepaper_v1.2_t.pdf [Accessed 09/10/2020].

23. Willie, P. (2019) Can all sectors of the hospitality and tourism industry be influenced by the innovation of Blockchain technology? Worldwide Hospitality and Tourism Themes, 11(2), pp. 112-120. https://doi.org/10.1108/WHATT-11-2018-0077. 